\title{
Calculation of the Choked Back Pressure for Steam Turbines with Air Cooled Condensers
}

\author{
Haisheng Yang, Shuping Chang, Ruitao Wu \\ Thermal Technology Department, Hebei Electric Power Research Institute, Shijiazhuang, Hebei PRC. \\ Email: haisheng.yang@gmail.com, hbdyycsp@163.com, hbdyywrt@163.com \\ Received September, 2012
}

\begin{abstract}
The choked back pressure characteristic of the steam turbine unit with air cooled condenser is very different with the unit with wet cooling technology, and the understanding of the choked back pressure performance change with operation load is important to guide the economic operation of the unit. One simplified Variable Operation Condition Analysis Method was put forward for calculation of the unit output-turbine back pressure characteristics. Based on this method, the choked back pressure for each operation load can be determined. An example was given for a super-critical, regenerative single-shaft, 2-casing with 2-exhaust steam turbine generation unit with air cooled condenser. The calculation result was provided and compared with the result of the unit with wet cooling technology.
\end{abstract}

Keywords: Air Cooled Condenser; Steam Turbine; Choked Back Pressure Characteristic; Calculation

\section{Introduction}

In the past years, many of the large capacity steam turbine generation units with air-cooled condensers (ACCs) have been put into operation. It is shown that the safe operation of the units has been solved based on the operation experiences of the built units. On the other hand, very few attentions have been paid to the economic operation of the units with ACCs.

The major difference between the normal generation units with wet cooling technology and the units with ACCs is the steam turbine cold end design. For steam turbines with ACCs, special designed LP last blading is used, and the resulted characteristic of generator output versus turbine back pressure is completely different with the turbines using wet cooling technology. For choked back pressure the steam turbines with ACCs, few calculation and testing results has been published except some discussions on the theoretical principles of the choked back pressure.

Analysis of the change of turbine choked back pressure with the operation load can provide direct guidance on the economic operation of the generation units. This paper will analyze this issue theoretically, and provide a simplified method for calculation.

\section{Calculation Model of Choked Back Pressure for Steam Turbine with Air-cooled Condensers}

The turbine choked back pressure refers to the back pressure under which the steam flow speed at the exit of the turbine last blade is close to the local sound speed (Mach number around 0.95). The choked back pressure is related to the turbine inlet steam flow, that is, with the change of the inlet steam flow, the choked back pressure also varies.

Under normal operation condition, to keep the unit generator output stable and constant, the turbine inlet steam flow decreases with the lowering down of the turbine back pressure. But if the decreasing of back pressure exceeds a limit or the turbine choked back pressure, the steam inlet flow increases to maintain the same generator output.

For the units with ACCs, it is possible that the actual operation turbine back pressure is controlled below the choked back pressure limit, thus the unit performance will deteriorate. This could be avoided by lowering down of speed the ACC fans.

\subsection{The Calculation of the Steam Turbines Choked Back Pressure}

It can be deduced from the definition of the turbine choked back pressure that under the constant turbine inlet flow, the generator output will increase with the decreasing of the turbine back pressure until a critical back pressure value is reached. If the back pressure is continuously decreased than this critical back pressure, the unit power output will not increase but decrease. This critical back pressure can be regarded as the turbine choked back pressure. 
Therefore, the solution of the turbine choked back pressure can be change into a problem of how to determine the turbine power output change as a function of the turbine back pressure change.

When the impact of the turbine back pressure on unit output is considered, the commonly used calculation method adopted is described in [1], using the detailed variable operation analysis for the LP turbine last blading. Yet many of the difficulties need to be solved for this method, including:

- Many of the parameters related to the detailed variable operation analysis can't be collected.

- Many of the turbine last stages are curved and twisted. But many of the equations in the variable operation analysis for the last stage are still deduced from one dimension condition. This can't guarantee the accuracy of the calculated results.

\subsection{The Application of the Simplified Variable Operation Condition Analysis Method}

When the turbine steam inlet control valves are set to a position and kept unchanged (such as under the boiler follow operation mode), the flow passage area of the control stages and thus the steam inlet flow is constant when the turbine back pressure has some variations. The control stage efficiency can be regarded as constant, and the efficiency of the following turbine pressure stages is unchanged under turbine operation change conditions. The only exception is the LP turbine last stage, where the operation condition of the LP last stage will be influenced by the turbine back pressure change and the stage efficiency will be affected. In summary, the LP turbine is the only part where the turbine back pressure change has impact on turbine work.

The LP turbine expansion process is shown on Figure 1. Where the $h_{l p i}$ is the LP turbine inlet enthalpy under baseline condition, $p_{c}$ is the LP turbine back pressure under baseline condition, $h_{\text {elep }}$ is the LP turbine expansion line end point enthalpy under baseline condition, $\Delta h_{e l}$ is the LP turbine last stage exhaust loss under baseline condition, $\Delta h_{i d}$ is the LP turbine ideal enthalpy drop under baseline condition. The symbols with “'” represent the operation condition with changed turbine back pressure.

It can be shown on Figure 1 that during normal operation, when the LP turbine inlet steam condition is stable, the LP turbine exhaust volumetric flow will decrease with the rising of the turbine back pressure, which will lead to a smaller exhaust loss and thus a higher LP turbine efficiency $\eta_{\text {UEEP }}$ (indicated by the slope of the dashed line on Figure 1). For the LP turbine, it can be reasonably assumed that the LP turbine expansion line shape and expansion process is unchanged except for the expansion line end point. Thus the new LP turbine expansion line end point enthalpy can be calculated by:

$$
h_{\text {elep }}{ }^{\prime}=h_{j q}-\Delta h_{j r}{ }^{\prime} \times \eta_{\text {elep }}
$$

The steam parameters of the LP turbine extractions can be determined by similar method. First calculate the extraction steam flow for the LP heaters, and calculate the new corrected extraction pressure. The new extraction parameters can be found using the corrected extraction pressure and the same LP turbine expansion line. This iteration process continues until the parameter difference of the two iterations is lower than certain error.

Based on the LP turbine exhaust flow calculated in the above Simplified Variable Operation Condition Analysis, and the last stage exhaust loss curve provided by the turbine manufacture, the LP turbine last stage exhaust loss and the LP turbine used energy end point enthalpy $h_{\text {UEEP }}$ can be calculated, and the final generator output change can be calculated using the heat balance method.

This Simplified Variable Operation Condition Analysis Method considers both the LP turbine last stage exhaust loss change and the extraction steam flow change of the LP heaters for turbine back pressure change conditions.

This Simplified Variable Operation Condition Analysis Method is used in [2] for analyzing the generator output change with the turbine back pressure. The calculation result matches the real situation for one 600MW sub-critical generation unit.

\section{Calculation Example of Turbine Choked Back Pressure for Steam Turbine with ACCs}

For one example generation unit, the 660MW steam turbine is a critical, single-shaft, two-casing two-exhaust

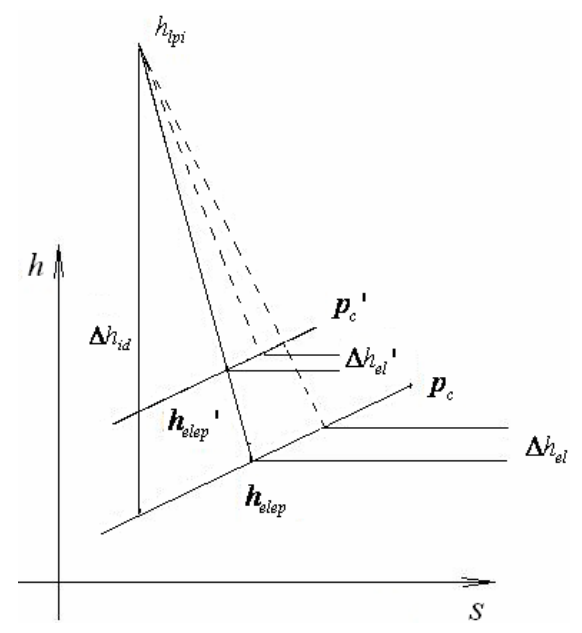

Figure 1. LP turbine expansion line under different LP turbine back pressure operation conditions.

condensing steam turbine with ACCs. There are totally 
28 stages in the turbine, including 1 control stage and 9 pressure stages for the HP turbine, 6 pressure stages for the IP turbine, and $2 \times 6$ pressure stages for the LP turbine. The LP turbine last blade has a height of $939.8 \mathrm{~mm}$. The steam turbine is controlled by nozzles. The steam flow into the four nozzle groups on the HP turbine is controlled by the four mail control valves. The ACC system is the mechanically drafted direct air-cooled system produced by the domestic manufacture.

The main design data of the steam turbine is summarized in Table 1.

\subsection{The Calculation Result of the Steam Turbines Choked Back Pressure}

Based on the turbine last stage exhaust loss curve, the turbine exhaust steam used energy end point enthalpy and the exhaust loss and the final generator output are calculated for various turbine back pressure operation conditions. For each load condition, the turbine back pressure corresponding to the maximum generator output can be regarded as the turbine choked back pressure.

Using this method, the turbine choked back pressures under different operation load conditions are calculated. On Figure 2, the generator output change with the back pressure is shown for various operation load conditions.
The turbine choked back pressure result is shown in Table 2 and Figure 3.

Table 1. Main design data of the steam turbine.

\begin{tabular}{lccc}
\hline \multicolumn{1}{c}{ Item } & Unit & THA & TRL \\
\hline Unit Output & $\mathrm{kW}$ & 660.01 & 660.00 \\
Unit Heat Rate & $\mathrm{kJ} / \mathrm{kWh}$ & 7778.31 & 8225.81 \\
Main Steam Pressure & $\mathrm{MPa}(\mathrm{a})$ & 24.20 & 24.20 \\
Hot Reheat Steam Pressure & $\mathrm{MPa}(\mathrm{a})$ & 3.71 & 3.94 \\
HP Turbine Exhaust Pressure & $\mathrm{MPa}(\mathrm{a})$ & 4.12 & 4.38 \\
Main Steam Temperature & ${ }^{\circ} \mathrm{C}$ & 566.00 & 566.00 \\
Hot Reheat Steam Temperature & ${ }^{\circ} \mathrm{C}$ & 566.00 & 566.00 \\
HP Turbine Exhaust Temperature & ${ }^{\circ} \mathrm{C}$ & 305.07 & 312.13 \\
Main Steam Flow & $\mathrm{t} / \mathrm{h}$ & 1878.42 & 2013.35 \\
Reheat Steam Flow & $\mathrm{t} / \mathrm{h}$ & 1600.90 & 1701.48 \\
Turbine Back Pressure & $\mathrm{kPa}$ & 16 & 33 \\
$\begin{array}{l}{ }^{\circ} \mathrm{C} \\
\text { LP Turbine Exhaust Enthalpy }\end{array}$ & $\mathrm{kJ} / \mathrm{kg}$ & 2454.67 & 2550.0 \\
$\begin{array}{l}\text { LP Turbine Exhaust Flow } \\
\text { Final Feedwater Temperature }\end{array}$ & $\mathrm{t} / \mathrm{h}$ & 1254.78 & 1349.40 \\
\hline Makeup Water & & 0 & 3 \\
\hline
\end{tabular}

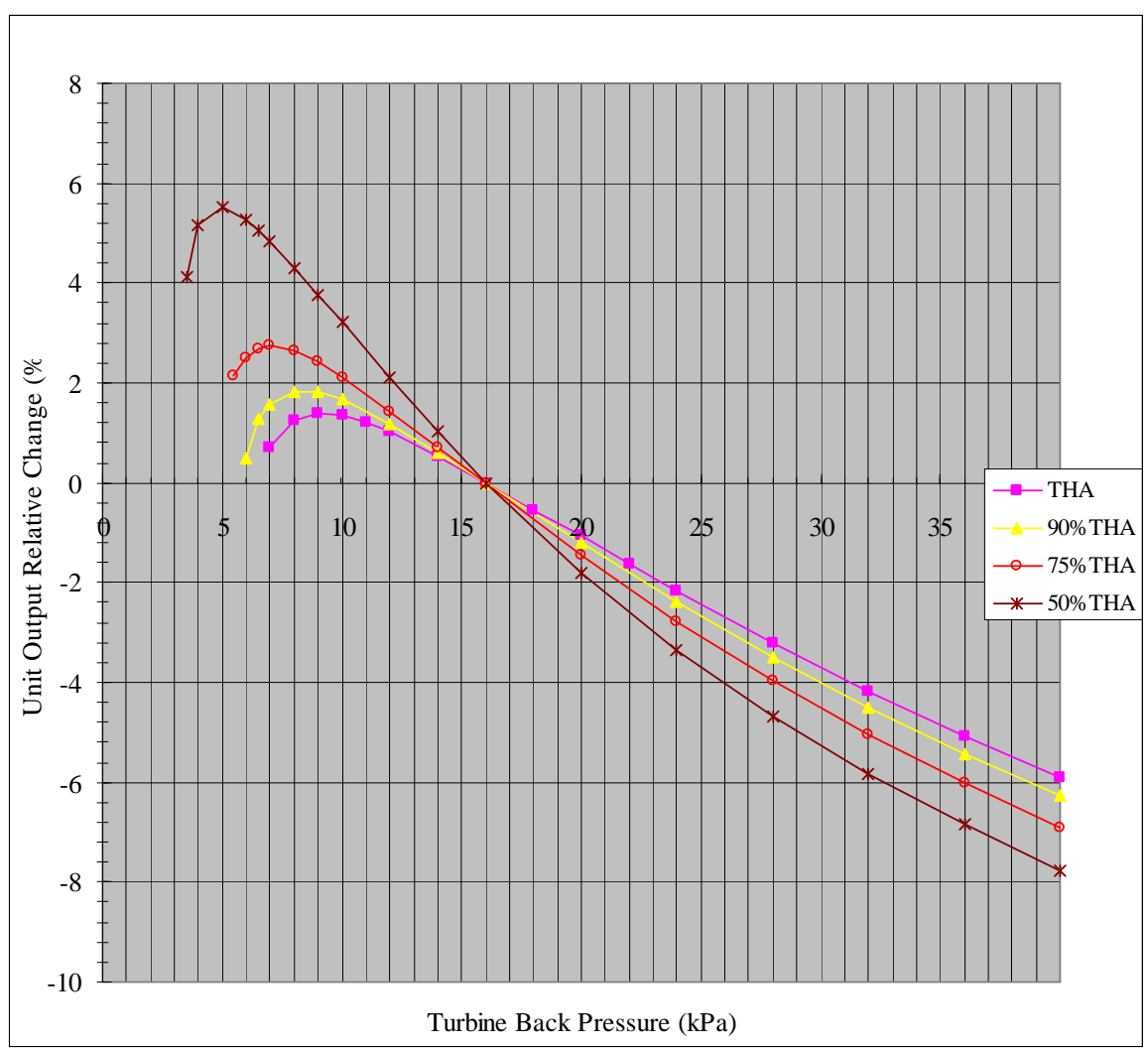

Figure 2. Performance curves of the unit output with turbine back pressure. 


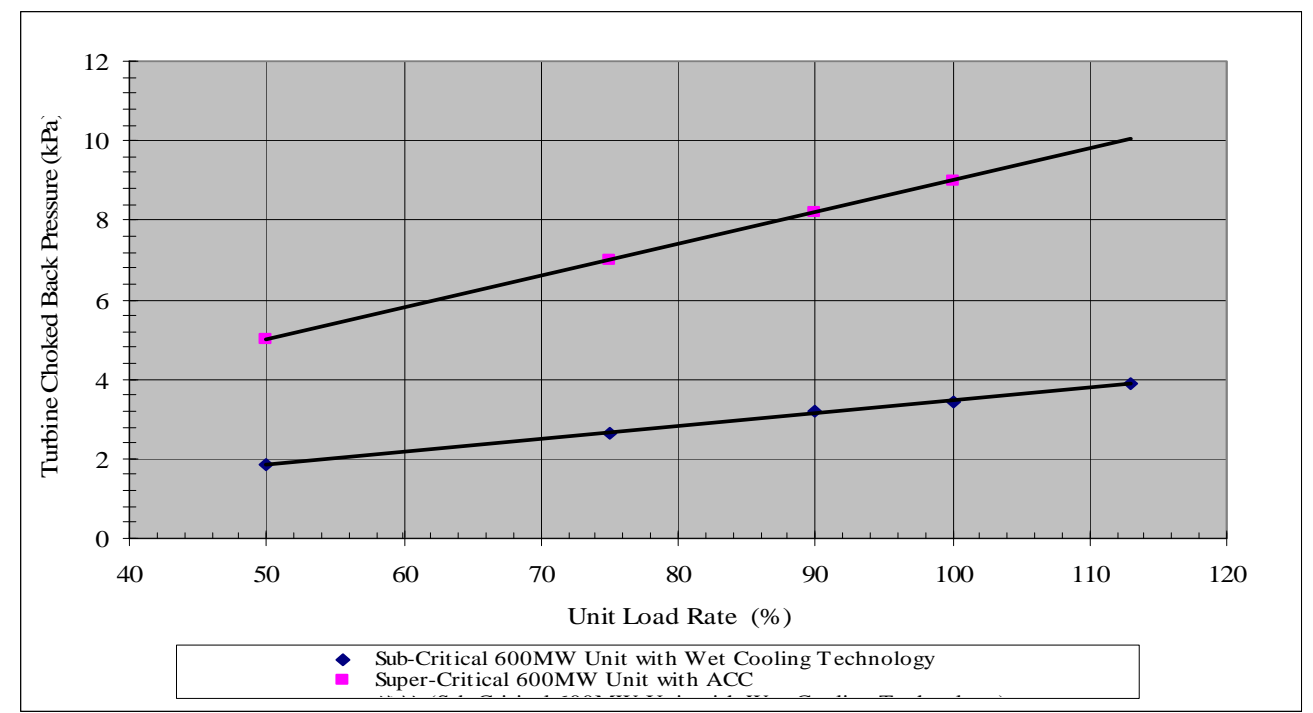

Figure 3. Performance curves of the turbine choked back pressure with unit load.

Table 2. Calculation results of choked back pressure under various operation loads.

\begin{tabular}{cc}
\hline Operation Load (\%) & Turbine Choked Back Pressure (kPa) \\
\hline 100 & 9.0 \\
90 & 8.2 \\
75 & 7.0 \\
50 & 5.0 \\
\hline
\end{tabular}

For comparison purpose, the choked back pressure for $600 \mathrm{MW}$ four-casing four-exhaust sub-critical generation unit with wet cooling technology is illustrated on Figure 3.

It can be shown from the Table 2 and Figure $\mathbf{3}$ that the turbine choked back pressure is in nearly linear relationship with the operation loads. For the choked back pressure curves, there is a significant increasing of the chocked pressure values for the units with ACCs compared with the similar curve of the units with wet cooling technology.

\section{Conclusions}

Based on the clear definition of the turbine choked back pressure, the solution of the choked back pressure is changed into a problem of how to determine the turbine power output change as a function of the turbine back pressure change.

The proposed simplified variable operation condition analysis method is adopted for one sub-critical generation unit with ACCs. The performance curve of the power output versus the turbine back pressure under various operation loads is given, and curve of the turbine choked back pressure under different loads is provided. These curves provide valuable guidance for the economic operation of the power plant units.

\section{REFERENCES}

[1] H. Lin, "Calculation and Correction of the Impact of Turbine Back Pressure on Turbine Output," Turbine Technology, Harbin China, Vol. 46 No. 1, 2004, pp. 18-21.

[2] H. S. Yang, "Simplified Calculation Method of Turbine Back Pressure Correction Curves,” Turbine Technology. Harbin China, Vol. 49, No. 1, 2007, pp. 32-34. 